Original Article

\title{
PREVALENCE AND TYPE OF MICROORGANISMS ISOLATED FROM PHONES USED BY MEDICAL STAFFS/STUDENTS, WORKING/STUDYING IN A TERTIARY CARE CENTER
}

\author{
ANUSHA CAROLINE SAROJ S., R. PREETHY, ROSY VENNILA \\ Department of Microbiology, Saveetha Medical College and Hospital, Thandalam, Kanchipuram District, Tamil Nadu 602105 \\ Email: drpr.ammu@gmail.com
}

Received: 15 Sep 2020, Revised and Accepted: 17 Nov 2020

\section{ABSTRACT}

Objective: To find out the prevalence and type of microorganisms isolated from mobile phones used by health care workers, students working/studying in a tertiary care center as well as to find the rate of contamination of the hands of the individual.

Methods: Swabs moistened with sterile saline was used to swab on phone surfaces and was incubated using standard culture and identification methods. The respective user was instructed to imprint their fingers of both hands on plates of culture media. These were incubated and processed as per standard culture methods.

Results: The most common isolated microorganisms in both groups were Coagulase-negative Staphylococci (CoNS) and MSSA. Among Mobile phones of HCW, the highest contamination rate was noted in physicians $70 \%$ followed by Intensive care doctors $60 \%$, and Nurses. Finger impression growth rate was observed high among Nurses $70 \%$ followed by Intensive care doctors $60 \%$ and physicians $40 \%$.

Conclusion: There is found to be a moderate contamination rate of mobile phones and fingers with pathogenic bacteria as well as normal flora of skin isolated from health care workers. Mobile phones and hands of Health care workers serve as a potential reservoir for hospital-acquired infections as multi-drug resistant pathogenic bacteria. In order to reduce the incidence of nosocomial infections, there should be an implementation of handwashing practices.

Keywords: Health care workers, Coagulase-negative staphylococci, Nosocomial infections, Multi-drug resistant

(C) 2021 The Authors. Published by Innovare Academic Sciences Pvt Ltd. This is an open access article under the CC BY license (https://creativecommons.org/licenses/by/4.0/)

DOI: https://dx.doi.org/10.22159/ijcpr.2021v13i1.40815. Journal homepage: https://innovareacademics.in/journals/index.php/ijcpr

\section{INTRODUCTION}

A mobile phone is a long-range personal telecommunication device, easy to handle, and affordable to everybody and play an inevitable and irreplaceable role in each one's social and professional life. Nowadays, mobile phones have become an inevitable part of our lives. Their number per capita is often much larger than the population of a country [1]. Mobile phones generate heat, which gives the microorganisms an incubating ground to live upon. The moisture obtained while the phone is left open and the nutrition obtained in case of food spillage over the phones serve as a prime breeding ground. The contamination of the mobile phones of health care workers or students could also lead to nosocomial infections, which results in a declined quality of health care. The fingers from the hands of the individual using the mobile phone, being the major source of contamination from the fingers to the mobile phone surface and vice versa was also considered in the study [2].

The telecom regulatory authority of India (TRAI) in its annual report (2009-2010) gave an increase of mobile phone users in India by $49.5 \%$ in just one year [3]. In fact, the number of mobile phones is at a much higher rate comparing with the population. An average person spends $2 \mathrm{~h}$ and 51 min per day on their mobile device. $22 \%$ of users check their phones every few minutes, and $51 \%$ of users look at it a few times per hour. It suffices to say that we are getting dangerously close to becoming addicted. Also, the device is almost all day kept close to the user's body and held intimately into the hands, carrying sweat.

Health care professional's mobile phones can also be easily and quickly contaminated by microorganisms from the hospital environment, patients, and medical devices since they use constantly for a medical dictionary, hand reference for drug, laboratory, and imaging results, and other work-related issues in a clinical setup [4-6].

Considering health care centers, mobile phones have been of a good use for faster communication, at times within the hospital and it has led to improved quality of health care. However, there could be certain disadvantages to be emphasized, such as the transmission of microorganisms from patients to the health care workers' mobile phones and vice versa. They are widely used as a nonmedical portable device, being so close in contact with the body. There is now an emerging international consensus that mobile phone use in hospitals, with appropriate precautions, can improve patient care and pose minimal risks [7].

Disinfection of mobile phones of health care workers is not done quite often as it should be. Proper disinfection and sanitization of mobile phones and hands could result in lower rates of contamination and improved health care. Decontamination of mobile phones can be done with alcoholic disinfectants and in a study, it was noted that ethyl alcohol was $100 \%$ effective [8].

As per a new study scheduled for publication, the studies found a cocktail of live germs, including Staphylococcus and E. coli microbes on phones. The study recommends that phones should be decontaminated daily and regularly with either 70\% isopropyl or by sanitising with (ultraviolet) devices like PhoneSoap. The procedure is that to first clean the phone with a soft, slightly damp lint-free microfibre cloth, then to use a disinfecting wipe to make it germs free after you are done cleaning. In case of lack of disinfecting wipes, rubbing alcohol prepared using $70 \%$ isopropyl can be used to spray and disinfect before the solution dries out. The use of sanitizers to disinfect hands and frequent hand washing following the 7 step procedure can reduce the contamination rate and infection spread to a greater extent. Hand washing is considered one of the best ways of protection against various microorganisms. Hence the main aim of this study is to find out the prevalence and type of microorganisms obtained from the mobile phones used by health care workers or students working or studying in a tertiary care center.

\section{MATERIALS AND METHODS}

\section{Study design and population}

After getting ethical approval from the institutional review board, A prospective study was conducted in a tertiary care teaching hospitalSaveetha Medical College and Hospital located in Thandalam, 
Kanchipuram district, Tamil Nadu-602105 from June 2020 to August 2020 for a period of 3 mo.

The study included a total of 75 samples from mobile phones and finger prints of both hands of HCWs i.e., 20 microbiologists, 10 physicians, 5 intensive care doctors, 20 nurses, medical technicians and lab workers, 13 sweepers and 7 medical students aged from 20 to 60 .

\section{Methods}

Detailed explanation of the procedure and study was given to the participant and consent forms were signed before collection of samples from the individual. Sterile latex gloves were worn before the collection of samples. Samples from mobile phones and fingerprints from the ventral surface of the respective individual were collected. Samples from mobile phones were collected using a sterile swab, which was moistened with sterile physiological saline and was rubbed on both the surfaces of the mobile phone. The swab samples were immediately streaked into blood agar and MacConkey agar plates. For the collection of fingerprint sample, the respective individual was instructed to imprint their fingers of both hands on the Blood agar and MacConkey agar plates, respectively. The agar plates were labeled accordingly and were incubated at 37 degrees Celsius for $24 \mathrm{~h}$. The microorganisms isolated were identified as per the standard laboratory guidelines.

\section{RESULTS}

A total of 75 mobile phones and 75 finger impressions of HCWs were tested among, 20 microbiologists, 10 physicians, 5 intensive care doctors, 20 nurses, medical technicians and lab workers,13 sweepers and 7 medical students.

\section{FIG showing sample collection among HCW}
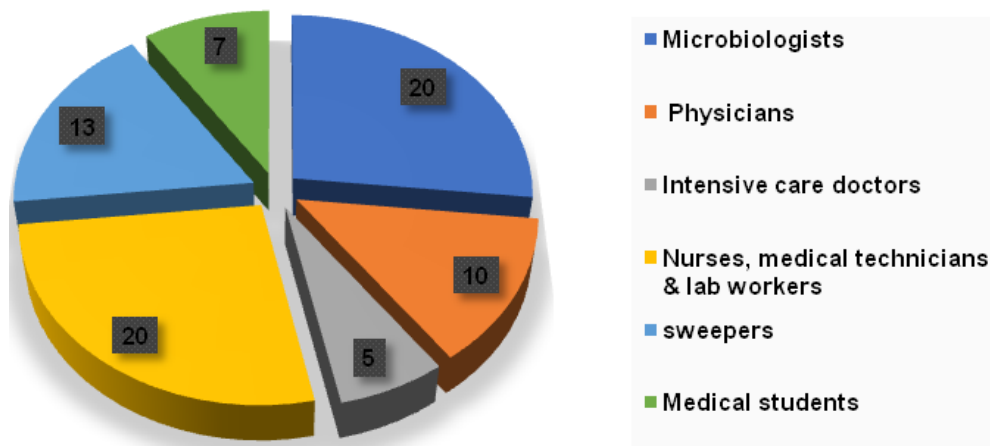

Fig. 1: Of 75 isolates, 50 (66.6\%) mobile phones and 45 (60\%) finger impressions showed growth of microorganism

The various bacterial isolates recovered from mobile phones of HCWs were, coagulase-negative Staphylococcus (CoNS) (24; 548\%), followed by methicillin-sensitive $S$ aureus (MSSA) (11; $22 \%)$, Klebsiella pneumoniae (7;14\%), Pseudomonas auerginosa (2; $4 \%)$, MRSA $(5 ; 10 \%)$. CoNS were the most prevalent bacteria isolated from mobile phones (48\%) and hands (57.7\%), which correlates with the results $(48 \%)$ of Srikanth et al. In the present study, the mobile phones and fingerprints of HCWs showed a high contamination rate by bacteria. This correlates with the results of studies by Elkholy and Ewees from Egypt (96.5\%).

Table 1: Showing various organism isolated from mobile phones and fingerprints of HCW

\begin{tabular}{lll}
\hline Organism & No of isolates from mobile 50 (66.6\%) & Isolates from fingerprints 45 (60\%) \\
\hline CoNS & $24(48 \%)$ & $26(57.7 \%)$ \\
MSSA & $11(22 \%)$ & $15(33.3 \%)$ \\
Klebsiella pneumoniae & $7(14 \%)$ & - \\
Pseudomonas auerginosa & $2(4 \%)$ & $1(2.2 \%)$ \\
MRSA & $5(10 \%)$ & $1(2.2 \%)$ \\
E. coli & $1(2 \%)$ & $2(4.4 \%)$ \\
\hline
\end{tabular}

Table 2: Showing growth among mobile phones and fingerprints of various HCW

\begin{tabular}{|c|c|c|c|}
\hline HCW & Total sample & Growth in mobile phone & Growth in finger prints \\
\hline Microbiologists & 20 & $8(40 \%)$ & $4(20 \%)$ \\
\hline Physicians & 10 & $7(70 \%)$ & $4(40 \%)$ \\
\hline Intensive care doctors & 5 & $3(60 \%)$ & $3(60 \%)$ \\
\hline Nurses, medical technicians and lab workers & 20 & $11(55 \%)$ & $14(70 \%)$ \\
\hline Sweepers & 13 & $6(46 \%)$ & $3(23 \%)$ \\
\hline Medical students & 7 & $3(42 \%)$ & $2(28 \%)$ \\
\hline
\end{tabular}

Total of 5 MRSA was recovered from mobile phones of 2 nurses, 2 ICU doctors and one Physician and one MRSA was isolates from fingerprints from staff nurse.

Significant difference was found between groups from the results of their Mobile phones and finger imprints.

Among Mobile phones of $75 \mathrm{HCW}$, the highest contamination rate was noted in physicians $70 \%$ followed by Intensive care doctors $60 \%$, and
Nurses, medical technicians and lab workers 55\% The highest contamination rate in doctors could be due to patient overload, improper disinfection usage, inappropriate hand hygiene practice, no restricting use of mobile phones in clinically sensitive areas.

Of 75 contaminated finger impressions of their hands, the highest growth rate was observed in Nurses, medical technicians, lab workers, support staff $70 \%$ followed by Intensive care doctors $60 \%$, 
physicians $40 \%$ and medical students, microbiologists. High contamination rate in the hands of support staff could be unawareness toward the nosocomial infection control policy, sensitization, and lack of education in implementation of it.

\section{DISCUSSION}

Mobile phones are a device that is been widely used in the health care facility as a non-medical device, having no restrictions for use regardless of microbial load. It has been increasingly used as a means of collecting epidemiological data and monitoring diseases both in the community and in the health care facility. The lack of restriction may be referred to little awareness about potential risks posed by mobile phones' microbial contamination and their role as a vehicle for transmission of infections [9].

This study revealed that $60 \%$ of the mobile phones of health care workers were contaminated with microorganisms, similar to a study conducted by Tambe and Pai (2012) 83\% of screened mobile phones of the HCWs showed bacterial or/and fungal contamination. Similar findings were reported from Hawassa, Ethiopia, Gondar, Ethiopia, India, Nigeria and Iran. A variation might be observed due to the difference in adherence to infection prevention like sanitation, hand washing and awareness of the role of mobile phones in microbial transmission. The study also revealed that mobile phones get contaminated through hands and vice versa as bacterial flora detected in both are similar.

In a study done by Meadow et al. (2014) they characterized microbial communities on smartphone touch screens to determine whether there was significant overlap with the skin microbiome sampled directly from their owners. They found that about $22 \%$ of the bacterial on participants' fingers were also present on their own phones. Beckstrom et al. (2013) in their study of bacterial contamination of the parent's cell phone in the NICU and the effectiveness of an antimicrobial gel in reducing transmission to the hands, found that all cell phones demonstrated bacterial contamination.

In addition, in our study highest finger impression growth rate was observed in nurses, medical technicians, lab workers, support staff ( $67 \%$ and $78 \%$, respectively). This agreed with the findings of Rosenthal et al. in 2005 and in 2013; where compliance was higher among nurses than among other HCWs.

Lower rates of contamination were found by Kokate et al. (2012) and Mark et al. where both reported $60 \%$ contamination rates of examined mobile phones of HCWs.

In the current study, CoNS was detected in $48 \%$ of the samples from mobile and fingerprints, followed by MSSA $(22 \%)$, similar to the result reported by a study by Bhoonderowa et al. (2014) were CoNS was the most prevalent $(69 \%)$ bacteria from mobile phones of volunteers in the community. In 2014, a study carried out by Raghavendra et al. revealed that $52 \%$ of the examined mobile phones of HCWs were contaminated by S. aureus.

\section{CONCLUSION}

Mobile phones and hands of health care workers serve as a potential reservoir for hospital-acquired infections as multi-drug resistant pathogenic bacteria as well as normal flora of skin were recovered. The contaminated mobile phones and hands pose increased risk epidemiologically, and their use should be limited to emergency situations only with due care to reduce the risk of transmission of nosocomial pathogens as complete restriction may prove impracticable. The use of a headset during hospital hours is a good alternative for using mobile phones. Strict infection control measures, such as hand washing must be advocated [10]. The infection control practices and simple measures such as proper hand hygiene practice and regular decontamination and cleaning of mobile phones with alcohol-containing disinfectant (70\% isopropyl alcohol) may reduce the risk of hospital-acquired infection caused by these devices [11].

There is an urgent need to educate awareness among the HCWs about the potential role of phones in the transmission of infectious agents in and outside hospital. Infection control committee can step forward to make clear-cut guidelines regarding the use of phones in health-care setup. There is a need to produce mobile phones with protective material against bacterial contamination.

\section{ACKNOWLEDGEMENT}

I sincerely thank Saveetha Medical College and Hospital, Chennai, for their continued support in this study. I also extend heartfelt gratitude to, Dr. R. Preethy, the Postgraduate Department of Microbiology and Dr. Rosy Vennila Head of Department of Microbiology for their invaluable guidance in this study.

\section{FUNDING}

Nil

\section{AUTHORS CONTRIBUTIONS}

All the authors have contributed equally.

\section{CONFLICTS OF INTERESTS}

There are no conflicts of interest.

\section{REFERENCES}

1. Kotris I, Drenjancevic D, Talapko J, Bukovski S. Identification of microorganisms on mobile phones of intensive care unit health care workers and medical students in the tertiary hospital. Med Glas (Zenica) 2017;14:85-90.

2. Pal S, Juyal D, Adekhandi S. Mobile phones: reservoirs for the transmission of nosocomial pathogens. Adv Biomed Res 2015;4:144.

3. The telecom regulatory authority of India (TRAI) in its annual report gave an increase of mobile phone users in India by $49.5 \%$ in just one year; 2010.

4. Bodena D, Teklemariam Z, Balakrishnan S. Bacterial contamination of mobile phones of health professionals in Eastern Ethiopia: antimicrobial susceptibility and associated factors. Trop Med Health 2019;47:15.

5. Ulger F, Esen S, Dilek A. Are we aware of how contaminated our mobile phones with nosocomial pathogens? Ann Clin Microbiol Antimicrob 2009;8:7.

6. Ulger F, Dilek A, Esen S, Sunbul M, Leblebicioglu H. Are healthcare workers' mobile phones a potential source of nosocomial infections? Review of the literature. J Infect Dev Ctries 2015;9:1046-53.

7. Ramesh J, Carter AO, Campbell MH, Gibbons N, Powlett C, Moseley $\mathrm{H} \mathrm{Sr}$, et al. Use of mobile phones by medical staff at queen elizabeth Hospital, Barbados: evidence for both benefit and harm. J Hosp Infect 2008;70:160-5.

8. Angadi Kalpana M, Misra Rabindranath, Gupta Urvashi, Jadhav Savita, Sardar Moumita. Study of the role of mobile phones in the transmission of Hospital-acquired infections. Med J 2014;7:435-8.

9. Badr RI, Ibrahim Badr H, Ali NM. Mobile phones and nosocomial infections. Int J Infection Control 2012;8:295.

10. Nwankwo EO, Ekwunife N, Mofolorunsho KC. Nosocomial pathogens associated with the mobile phones of healthcare workers in a hospital in Anyigba, Kogi State, Nigeria. J Epidemiol Glob Health 2014;4:135-40.

11. Shah PD, Shaikh NM, Dholaria KV. Microorganisms isolated from mobile phones and hands of health-care workers in a tertiary care hospital of Ahmedabad, Gujarat, India. Indian J Public Health 2019;63:147-50. 